\title{
Forced interruption and reunion: the effect of COVID-pandemic related restrictions on ongoing psychodrama groups in Hungary
}

\author{
Edit Szathmári D Veronika Ferencz • Orhidea Edith Kiss
}

Accepted: 14 December 2021 / Published online: 7 February 2022

(C) The Author(s) 2022

\begin{abstract}
The COVID-pandemic measures, restricting physical distancing and lockdown in 2020, had fundamental effects on all aspects of life, including face-to-face group methods, like psychodrama. This situation provided a unique opportunity to study the effects of unavoidable environmental interruptions on psychodrama groups and the leaders' roles and responses in such situations. We invited Hungarian psychodrama leaders to describe their experiences with their ongoing groups. They completed two online questionnaires; the first was after the initial lock-down and the second during the next wave of the pandemic. Results showed the risk factors and protection regarding the stress on leaders during the interruption and their immediate and lasting consequences after the reunion of the group. In addition, to using role reversal and mirror technique questions, the emerging themes and patterns of their experiences and their key learning regarding interruption and online group sessions were also identified.
\end{abstract}

Keywords Psychodrama - Online group · Forced interruption · Reunion · COVID

Edit Szathmári, MA · Veronika Ferencz, MA

Doctoral School of Psychology, ELTE Eötvös Loránd University, Budapest, Hungary

E-Mail: veronika@student.elte.hu

Edit Szathmári, MA $(\varangle) \cdot$ Veronika Ferencz, MA · Orhidea Edith Kiss, PhD

Institute of Psychology, ELTE Eötvös Loránd University, Budapest, Hungary

E-Mail: szathmari.edit@ppk.elte.hu

Orhidea Edith Kiss, PhD

E-Mail: kiss.orhidea@ppk.elte.hu 


\section{Personal introduction}

The idea, underpinning this research, has roots in personal experiences. The first two authors were leading two ongoing psychodrama groups when the first restrictions of holding face-to-face group sessions were announced due to the COVIDpandemic. While dealing with the groups as leaders, as researchers they wanted to trace the learning from this unique situation. Therefore, we would like to thank our fellow psychodrama leaders for their participation in this research and, also, to thank the Hungarian Psychodrama Association for their contribution in finding our participants.

\section{Background}

The COVID-pandemic, as an unprecedented phenomenon, means that the literature is relatively current and inherently incomplete. COVID's immediate and lasting effects has been investigated and evaluated from various scientific perspectives. However, we are still in the first phases of a long journey of research. This research journey requires that we learn what exactly we are facing and what effective mechanisms can be used for coping and adapting.

In our study we examined the effects of unavoidable environmental interruptions on psychodrama groups and the leaders' role. Relevant literature and research of psychodrama included an overview of the methods that can be used to help coping with the crisis caused by the pandemic (Drakulić and Radman 2020). According to the authors preventing the re-traumatization of the protagonist is of high importance; hence the elements of regular interventions had to be modified and new, transformative roles had to be activated on the way to recovery.

Another element of our study is online group therapy, which was a brand-new field for professionals, especially given that psychodrama is a method built on personal presence and relational contact. Literature related to online work, was mostly about sociodrama; for example, Castro, Vidal, Silveira and Oliveira (2020) report a video conference (Zoom) session with 36 participants, where they managed to create spaces for reorganizing social roles.

We believed that the pandemic, as a collective experience, had a threatening impact. From the literature related to social psychological dynamics in groups, we found general patterns on perceived threat (e.g., collective nostalgia), which relates to stronger feelings of in-group continuity via in-group belonging (Smeekes et al. 2018).

The interruption of psychodrama groups (or any kind of dynamic process) inevitably affects the cohesion of the group. The impact on treatment outcome (Burlingame, McClendon and Yang 2018) was found to be moderated by leader interventions to increase cohesion, theoretical orientation, type of group, emphasis on group interaction, and frequency or number of group sessions.

Similarly, the effects of forced or premature termination of therapy had to be considered and there was much relevant information found. This included literature that focussed on therapist-induced termination (Fieldstiel 2005); forced termination 
due to the death of the therapist (Garcia-Lawson, Lane and Koetting 2000); or the client deciding on early dropout from the group (McCallum, Piper, Ogrodniczuk and Joyce 2002; Rice 1996; Yalom 1966).

The crisis caused by the pandemic put increased stress on leaders in general and on group leaders in particular. Our deeper understanding of the factors involved in effective crisis leadership, for instance role-taking and decision-making accuracy, came mostly from business environments (e.g. Hadley, Pittinsky, Sommer and Zhu 2011). However, we didn't find literature on sudden, unexpected interruption or termination of the group process, and its effect on leaders' strategies.

Arising from our own experience as leaders, and the relative lack of literature, we formulated the following two research questions for our study:

Q1 What are the effects of the forced interruption on the group?

Q2 What is the leaders' role in such situation?

\section{Research design}

We asked psychodrama leaders to fill online questionnaires at two points of time, which fitted into the COVID-pandemic related restrictions. The first wave of restrictions in Hungary took place in March-June 2020; at this time, it was not allowed to hold face-to-face group sessions, being the first forced interruption. In order to gather data, the first questionnaire was sent to the research participants in AugustSeptember; this timing focussed on the period of lockdown restrictions and on their first impressions after the group reunion. According to the original research plan, the second questionnaire was designed to measure the lasting effects of the first wave restrictions, in December 2020.

Due to the progression of the pandemic, December also happened to be the time of the second wave of restrictions, which started in November 2020. This allowed us to learn not only about the longer-term effects of the first interruption, but also about the solutions leaders used during the second wave of restrictions.

\section{Questionnaires}

In both questionnaires, we asked the age, gender, psychodrama training and experience of the pair of leaders of the given group and basic frames of the group: aim (e.g. self-awareness), size, total duration in hours and hours already done at the beginning of the first wave.

There were questions about the quality of leaders' experience with the group and the quality of cooperation between leaders before, during and after the March-June interruption on a five level Likert scale.

Regarding the interruption, communication forms, channels, and frequency with the group were asked. The perceived stress on leaders and group members during the interruption were measured on a five-point Likert scale. The leaders were asked 
to describe the incidences of COVID- or non-COVID related events among group members.

In the second questionnaire, focussing on the reunion, we asked them about the continuity of the group, form of group sessions and absence rate.

We used psychodrama techniques in the questionnaires: in the first one, participants formulated sentences from the role of the group and from their leader role (Moreno 1985, 1953) during the interruption. In both questionnaires, they formulated their perceptions from a mirror perspective (Moreno 1985, 1953) looking at the group and themselves after reunion. They created advice for themselves based on key learning from the interruption and the reunion experiences.

\section{Sample}

We received data on 29 groups (from 23 participants) in the first questionnaire, and on 23 groups (from 20 participants) in the second questionnaire. Among them there were 8 recurring groups, meaning that they appeared in both samples. Most of them were self-awareness groups; both samples had one training group as an exception, with the aim of preparing participants for leading psychodrama groups, whilst also working on their self-awareness.

All the groups had 10 to 16 participants and their duration ranged from 40 to $250 \mathrm{~h}$ (meaning from few months up to three years length); in the two samples, the hours done at the beginning of the first interruption ranged between 8 and $242 \mathrm{~h}$.

Table 1 Characteristics of the two samples

\begin{tabular}{|c|c|c|}
\hline & Sample 1 & Sample 2 \\
\hline Questionnaire focus & $\begin{array}{l}\text { Interruption characteristics } \\
\text { and immediate effects }\end{array}$ & $\begin{array}{l}\text { Lasting effects of } \\
\text { interruption }\end{array}$ \\
\hline Number of groups in the sample & 29 & 23 (8 recurring) \\
\hline \multirow[t]{2}{*}{ Aim of the groups } & 28 self-awareness & 22 self-awareness \\
\hline & 1 training & 1 training \\
\hline $\begin{array}{l}\text { Number of groups with members above } \\
65 \text { years }\end{array}$ & 3 & 1 \\
\hline $\begin{array}{l}\text { Average group duration in hours (mini- } \\
\text { mum-maximum) }\end{array}$ & $150(40-250)$ & $170(120-250)$ \\
\hline $\begin{array}{l}\text { Average hours done at the beginning of inter- } \\
\text { ruption } \\
\text { (minimum-maximum) }\end{array}$ & $65(10-170)$ & $87(8-242)$ \\
\hline \multirow[t]{3}{*}{ Gender of leader pairs } & 18 female-female & 11 female-female \\
\hline & 10 male-female & 12 male-female \\
\hline & $1 \mathrm{n} / \mathrm{a}$ & \\
\hline \multirow[t]{4}{*}{ Training of leader pairs } & 3 assistant-assistant & 0 assistant - assistant \\
\hline & 12 assistant-leader & 2 assistant-leader \\
\hline & 10 leader-leader & 11 leader-leader \\
\hline & 4 trainer-assistant/leader & $\begin{array}{l}10 \text { trainer-assistant/ } \\
\text { leader }\end{array}$ \\
\hline Number of groups with leaders above 65 years & 4 & 9 \\
\hline
\end{tabular}


There were female-female and male-female leader pairs with various combinations of psychodrama training: from assistant (beginner) level and more advanced leader to a senior trainer level.

In both samples, there were groups with members and leaders above the age of 65 years. During the time of the study, this age group was considered to be most endangered from the COVID disease health consequences (e.g. Crimmins 2020; Mallapaty 2020; Modi, Böhm, Ferraro, Stein and Seljak 2020). For the details of the samples' characteristics see Table 1.

\section{Results and discussion}

The results in this section are presented in two parts; firstly, looking at the data arising from analysis of the online questionnaires complemented by a discussion of the findings. The second part reports on the qualitative analysis from the text that was drawn from the open-ended questions in the questionnaire.

\subsection{Immediate effects of interruption}

The immediate effects of the interruption in March-June of 2020 were studied using the first questionnaire in August-September the same year. The results, measured on a five-point Likert scale, showed that stress on leaders, during the interruption, was a substantial and immediate effect, variously connected with other phenomena.

One potential risk of higher levels of stress on leaders, was the intensity of communication with the group during the interruption; this was found to be moderately correlated: $r(27)=0.586, p=0.001$. This connection could be explained by the tension from using new ways of communicating with the group. Another explanation might be due to the intense levels of communication from the group members, about their experiences of stress arising from COVID related events, which contributed to the stress leaders experienced. Supporting this interpretation, the number of online sessions during the interruption showed positive correlation with leaders' stress $(r(27)=0.510, p=0.004)$. The other group of risk factors of leaders' stress was connected to the group members' state and its perception by the leaders; these included crises among group members $(r(27)=0.471, p=0.010)$ and perceived stress on group members $(r(27)=0.546, p=0.002)$.

An important protective factor against stress was the effective cooperation between leaders: $r(27)=-0.405, p=0.029$.

A difficult consequence of the stress, on leaders during interruption, was the absence rate after reunion; identified $r(27)=0.429, p=0.020$. It is worth highlighting that the absence rate did not show significant correlation with any other variables in the study of immediate effects.

\subsection{Lasting effects of interruption}

The lasting effects of the interruption were studied in December 2020 and provided various results and findings about the reunion. 
Similar to the immediate effects, the stress on leaders during the interruption had negative lasting consequences on the quality of leaders' experiences with the group after reunion. These, measured on a five-level Likert scale, showed a moderate negative correlation between these two variables indicate: $r(17)=-0.529, p=0.020$. Another similarity to the immediate effects, the leaders' effective cooperation continued to play a positive long-term role. This quality from the beginning, before the first interruption, was a protective factor against absenteeism after reunion: $r(21)=-0.432$, $p=0.039$.

Importantly, we found that the reunion experience of leaders was connected to the continuity of the group; this meant the re-planned number of hours after reunion compared favourably to the original plan when the group started. The correlation between these two variables were $r(16)=0.474, p=0.047$, including groups that became shorter, followed original plan, or agreed an even longer duration after reunion.

The second interruption, during the second questionnaire, meant that leaders could indicate the form of group sessions they used. Results suggested that those leaders who communicated more often with the group during the first interruption were more likely to hold online sessions during the second interruption $r(21)=0.415$, $p=0.049$.

\subsection{Qualitative results}

We had five open questions in the questionnaire. We aimed to use psychodrama techniques to gain insight into the emotional experiences the group leaders: role reversal, mirror etc. The answers revealed a wide variety in length, wording, and content. To analyse these texts, we used thematic coding to identify the emerging topics. The results were visualized through word clouds (we used the free website worldclouds.com to create them), where the font size of each word is proportionate with their occurrence in the answers.

\subsubsection{In the role of the group}

The main topic that emerged in the role of the group was a feeling of ambivalence between losing the security of the well-known (missed, insecure, hard, apart) and in the meantime gaining strength from the coping process itself (became, strong, connected, etc.) (see Fig. 1). Online sessions appeared to be a transitional object for the group that one can hold onto in times of change.

\subsubsection{In the role of the leader}

Compared to being in the role of the group, the voice of the leader's role reported a stronger sense of responsibility: for the safety of both the members and the process. It can be seen in the codes worried, support, holding, provide, for instance in Fig. 2. 
Fig. 1 Frequency of themes mentioned in the role of the group

Fig. 2 Frequency of themes mentioned in the role of the leader
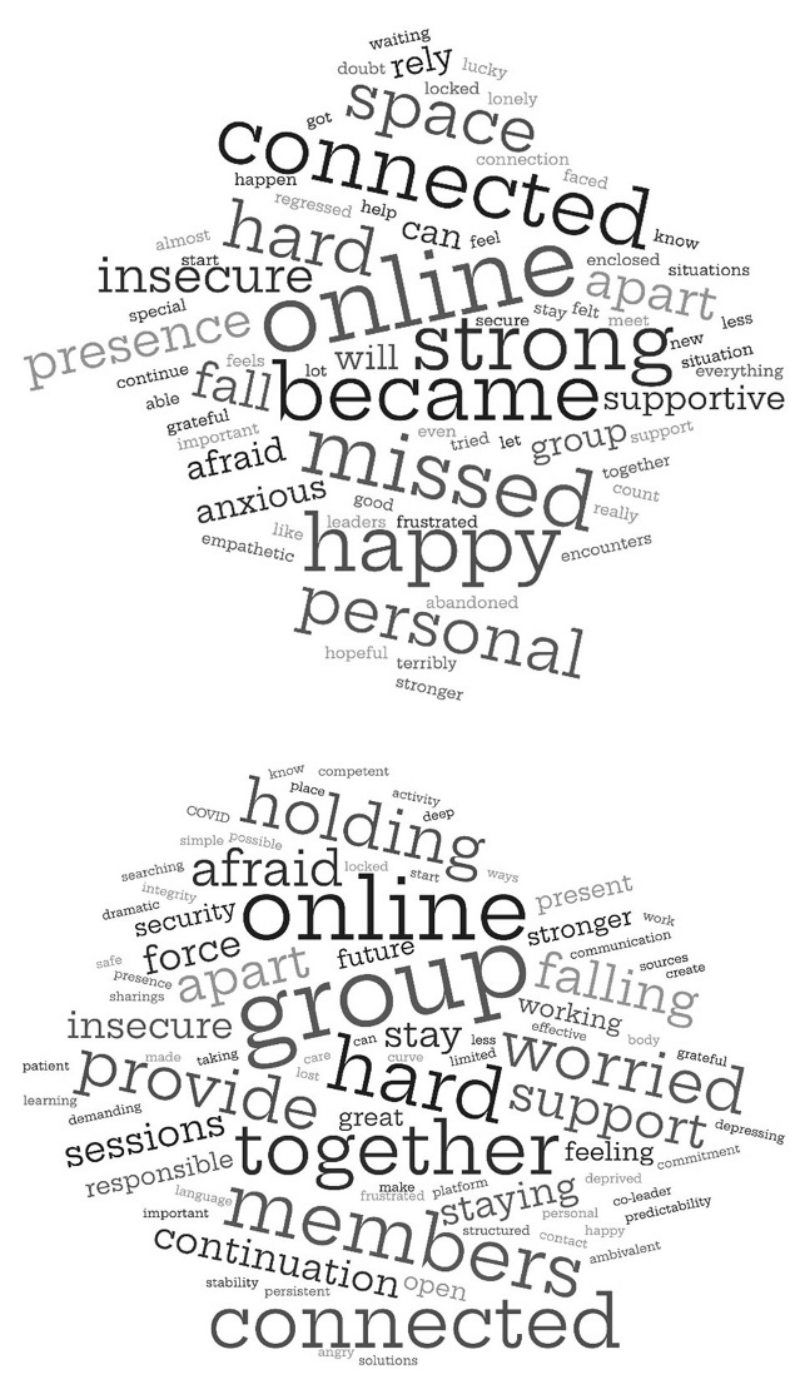

\subsubsection{In the mirror: first impressions of the group within the two months after reunion}

The first impressions of the leaders when, once again, they worked with the group face-to-face, formed two main patterns as Fig. 3 indicates. Many of them experienced difficulties due to the interruption of the working stage of the group process, this can be seen in the codes of stopped, interrupted, loss. In the meantime, a great inner cohesion was reported with the implication that the group commitment became even stronger during the interruption. 
Fig. 3 Frequency of themes mentioned in the mirror shortly after reunion
Fig. 4 Frequency of themes mentioned in the mirror six months after reunion
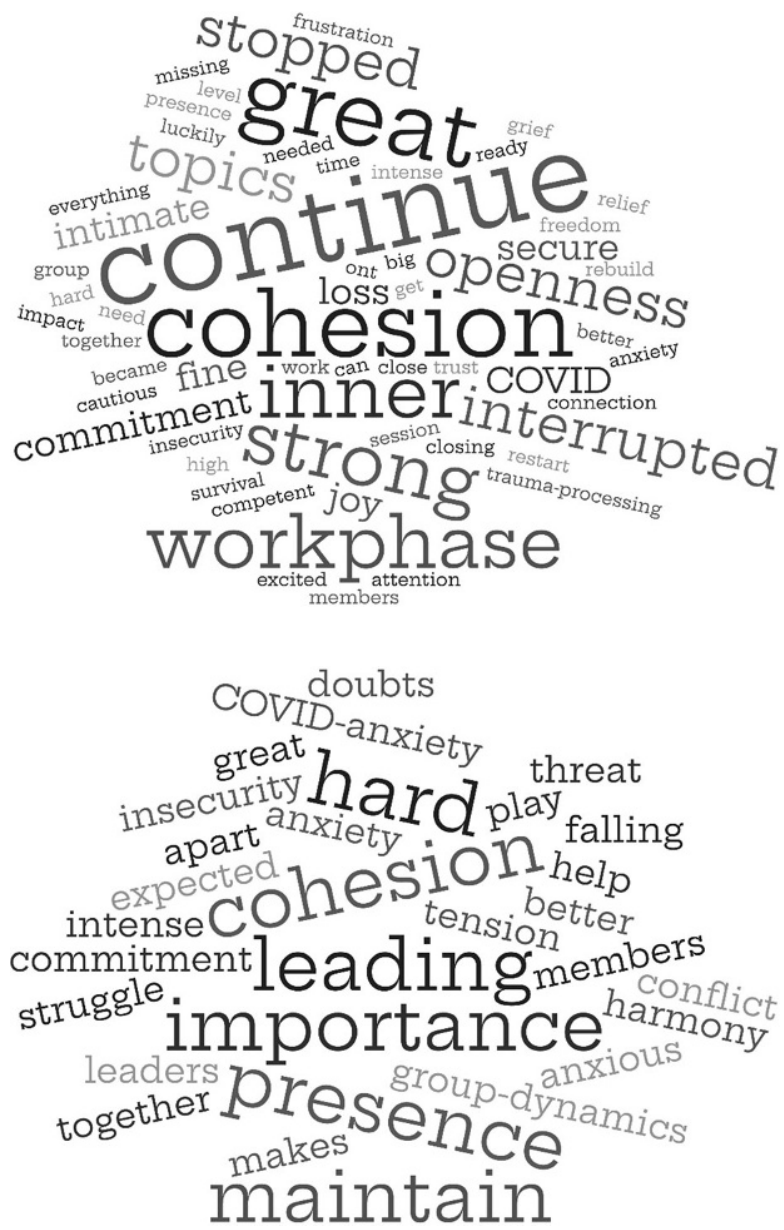

\subsubsection{In the mirror: Impressions of face-to face sessions six months after reunion}

In December, a few sessions later and six months after reunion, group cohesion was still reported strong and the importance of being present, meeting face-to-face became central, more than ever before. Leading the groups was demanding, due to emerging anxiety and intense group dynamics as can be seen in themes appearing in Fig. 4.

\subsubsection{Leaders' advice to themselves}

From the position of the second interruption in December, looking back on the entire experience from the first interruption through to the reunion, the leaders' advice to themselves focussed on the online work. Essential to go online as soon as possible and be more prepared to work online, as Fig. 5 indicates. 
Fig. 5 Frequency of themes mentioned in the leaders' advice for themselves

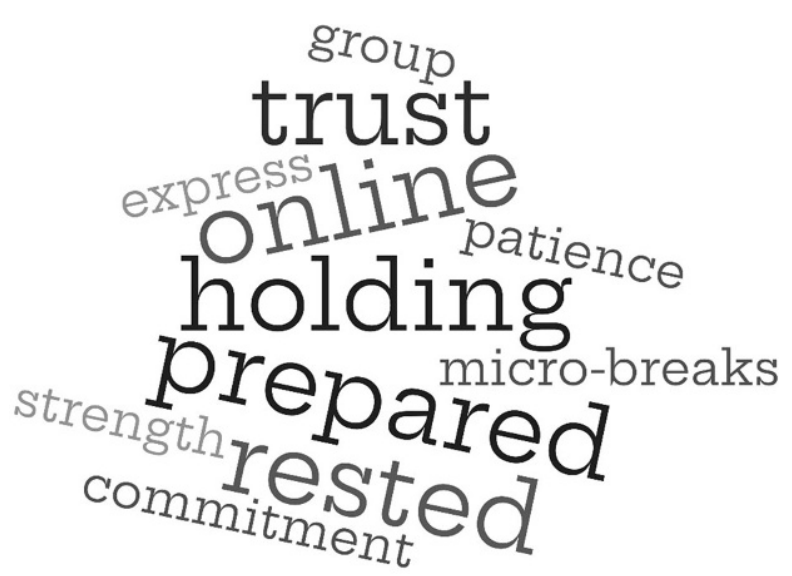

\section{Conclusions and further directions of research}

This study demonstrates that the unique, novel and unexpected external interruption, due to the impact of COVID, affected several ongoing psychodrama groups in Hungary; this gave an opportunity to investigate the impact on leaders, group members and the group process. Results indicated that the accommodation to new communication forms and the perception of group members' crisis and stress contributes to leaders' own levels of stress. Importantly, this study highlighted that the quality of the leaders' cooperation was a protective factor. These factors had lasting effects after the group reunion: affecting the continuity of the group, the absenteeism, and the quality of the leaders' experience.

Leaders' narratives explained the connections above. New forms of online communication and sessions served as tools for continuity and group cohesion, leaving higher levels of pressure on the leaders to respond to and create new forms of communication, in times of ambiguity. As a result, after the reunion, they either experienced difficulties in group process or an increased level of cohesion. Leaders learned that the sooner, or more frequent use of online channels, the better for group cohesion and continuity; this is supported by Burlingame, McClendon and Yang' (2018) findings related to the role of leaders' intervention and group interaction on group cohesion.

The interpretation of the results is limited by the sample size and the crosssectional nature of the study, although, the similar results two months and six months after interruption suggest that stress on leaders and cooperation between them play key roles in how the group process shapes after reunion.

Future research, especially on larger samples or in longitudinal setting may investigate the effects of further interruptions on the same group and the effects of various interventions and solutions of leaders, thus contributing to the higher level of adaptivity of self-awareness groups in times of uncertainty.

Funding Open access funding provided by Eötvös Loránd University. 
Open Access This article is licensed under a Creative Commons Attribution 4.0 International License, which permits use, sharing, adaptation, distribution and reproduction in any medium or format, as long as you give appropriate credit to the original author(s) and the source, provide a link to the Creative Commons licence, and indicate if changes were made. The images or other third party material in this article are included in the article's Creative Commons licence, unless indicated otherwise in a credit line to the material. If material is not included in the article's Creative Commons licence and your intended use is not permitted by statutory regulation or exceeds the permitted use, you will need to obtain permission directly from the copyright holder. To view a copy of this licence, visit http://creativecommons.org/licenses/by/4. $0 /$.

\section{Declarations}

Conflict of interest E. Szathmári, V. Ferencz and O.E. Kiss declare that they have no competing interests.

Ethical standards This article does not contain any studies with human participants or animals performed by any of the authors. All applicable international, national, and institutional ethical guidelines were followed. The datasets generated and analysed during the current study are available from the corresponding author on reasonable request. This research did not receive any specific grant from funding agencies in the public, commercial, or not-for-profit sectors.

\section{References}

Burlingame, G. M., McClendon, D. T., \& Yang, C. (2018). Cohesion in group therapy: A meta-analysis. Psychotherapy, 55(4), 384-398. https://doi.org/10.1037/pst0000173.

Castro, A., Pereira Vidal, G., da Silva da Silveira, B., \& de Oliveira, D. C. (2020). The survival through online sociodrama: COVID-19, what do you want to tell me? Revista Brasileira De Psicodrama, 28(3), 176-186. https://doi.org/10.15329/2318-0498.20209.

Crimmins, E. M. (2020). Age-related vulnerability to coronavirus disease 2019 (COVID-19): biological, contextual, and policy-related factors. Public Policy \& Aging Report, 30(4), 142-146. https://doi.org/ 10.1093/ppar/praa023.

Drakulić, A. M., \& Radman, V. (2020). Crisis psychodrama in the era of Covid-19. Psychiatria Danubina. https://doi.org/10.24869/psyd.2020.22.

Fieldsteel, N. D. (2005). When the therapist says goodbye. International Journal of Group Psychotherapy, 55(2), 245-279. https://doi.org/10.1521/ijgp.55.2.245.62191.

Garcia-Lawson, K. A., Lane, R.C., \& Koetting, M.G. (2000). Sudden death of the therapist: The effects on the patient. Journal of Contemporary Psychotherapy, 30, 85-103. https://doi.org/10.1023/ A: 1003605316813.

Hadley, C.N., Pittinsky, T.L., Sommer, S.A., \& Zhu, W. (2011). Measuring the efficacy of leaders to assess information and make decisions in a crisis: The C-LEAD scale. Leadership Quarterly, 22(4), 633-648. https://doi.org/10.1016/j.leaqua.2011.05.005.

Mallapaty, S. (2020). The coronavirus is most deadly if you are older and male-new data reveal the risks. Nature, 585, 16-17. https://doi.org/10.1038/d41586-020-02483-2.

McCallum, M., Piper, W.E., Ogrodniczuk, J. S., \& Joyce, A. S. (2002). Early process and dropping out from short-term group therapy for complicated grief. Group Dynamics: Theory, Research, and Practice, 6(3), 243-254. https://doi.org/10.1037/1089-2699.6.3.243.

Modi, C., Böhm, V., Ferraro, S., Stein, G., \& Seljak, U. (2020). How deadly is COVID-19? A rigorous analysis of excess mortality and age-dependent fatality rates in Italy. https://doi.org/10.1101/2020. 04.15.20067074. Manuscript preprint

Moreno, J. L. (1953). Who shall survive? Foundations of sociometry, group psychotherapy and sociodrama. Beacon: Beacon House.

Moreno, J. L. (1985). Psychodrama, first volume (4th edn.). Beacon: Beacon House.

Rice, C.A. (1996). Premature termination of group therapy: a clinical perspective. International Journal of Group Psychotherapy, 46(1), 5-23. https://doi.org/10.1080/00207284.1996.11491481.

Smeekes, A., Jetten, J., Verkuyten, M., Wohl, M., Jasinskaja-Lahti, I., Ariyanto, A., Autin, F., Ayub, N., Badea, C., Besta, T., Butera, F., Costa-Lopes, R., Cui, L., Fantini-Hauwel, C., Finchilescu, G., Gaertner, L., Gollwitzer, M., Gómez, Á., González, R., Hong, Y. Y., Jensen, D. H., Karasawa, M., Kessler, T., Klein, O., Lima, M., Renvik, T. A., Megevand, L., Morton, T., Paladino, P., Polya, T., Ruza, A., Shahrazad, W., Sharma, S., Teymoori, A., Torres, A. R., \& Van Der Bles, A. M. (2018). Regaining in- 
group continuity in times of anxiety about the group's future: A Study on the role of collective nostalgia across 27 countries. Social Psychology, 49(6), 311-329. https://doi.org/10.1027/1864-9335/ a000350.

Yalom, I.D. (1966). A study of group therapy dropouts. Archives of General Psychiatry, 14(4), 393-414. https://doi.org/10.1001/archpsyc.1966.01730100057008.
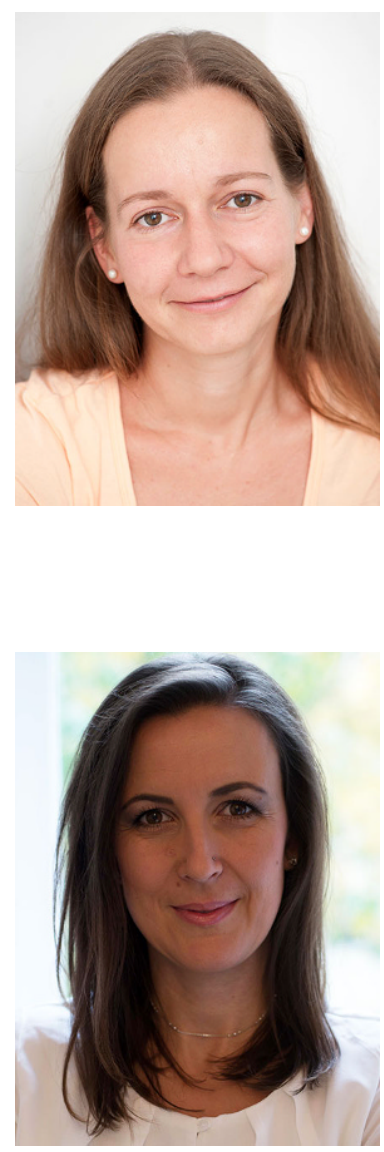

Edit Szathmári I am a psychologist (MA), I hold a degree in economics (MSc), and I am a certified psychodrama leader, we lead groups together with Veronika for three years. I do counselling for individuals, groups and organisations. I am a lecturer at Eötvös Loránd University, Budapest, currently working on my $\mathrm{PhD}$ research about the effect of becoming a leader on the personality.

Veronika Ferencz I am a psychologist (MA) with a specialization of counselling and health psychology, I have a degree in fairy tale therapy, and I am a certified psychodrama leader. I work with individuals and groups. Currently I am a PhD student (Eötvös Loránd University, Budapest) in qualitative research, my topic is about the resilience and active self-representation of women living under various forms of oppression. 


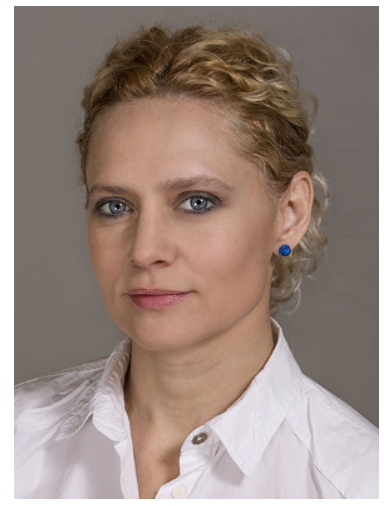

Orhidea Edith Kiss I am a psychologist, specialized in work- and organisational psychology. I am an associate professor at Eötvös Loránd University, Budapest and Head of the Department of Organisational and Leadership Psychology. In the focus of my recent research is the organisational trust. 